\title{
Preparation and properties of hybrid materials for high-rise constructions
}

\author{
Tatyana Matseevich ${ }^{1 *}$ \\ ${ }^{1}$ Moscow State University of Civil Engineering, Yaroslavskoe sh. 26, Moscow, 129337 Russia
}

\begin{abstract}
The theme of the research is important because it allows to use hybrid materials as finishing in the high-rise constructions. The aim of the study was the development of producing coloured hybrid materials based on liquid glass, a polyisocyanate, epoxy resin and 2.4toluylenediisocyanate. The detailed study of the process of stress relaxation at different temperatures in the range of $20-100^{\circ} \mathrm{C}$ was provided. The study found that the obtained materials are subject to the simplified technology. The materials easy to turn different colors, and dyes (e.g. Sudan blue G) are the catalysts for the curing process of the polymeric precursors. The materials have improved mechanical relaxation properties, possess different color and presentable, can be easily combined with inorganic base (concrete, metal). The limit of compressive strength varies from 32 to 17.5 $\mathrm{MPa}$ at a temperature of 20 to $100^{\circ} \mathrm{C}$. The values $\sigma_{\infty}$ are from 20.4 to 7.7 $\mathrm{MPa}$ within the temperature range from 20 to $100^{\circ} \mathrm{C}$. The physical parameters of materials were evaluated basing on the data of stress relaxation: the initial stress $\sigma_{0}$, which occurs at the end of the deformation to a predetermined value; quasi-equilibrium stress $\sigma_{\infty}$, which persists for a long time relaxation process. Obtained master curves provide prediction relaxation behavior for large durations of relaxation. The study obtained new results. So, the addition of epoxy resin in the composition of the precursor improves the properties of hybrid materials. By the method of IR spectroscopy identified chemical transformations in the course of obtaining the hybrid material. Evaluated mechanical performance of these materials is long-time. Applied modern physically-based memory functions, which perfectly describe the stress relaxation process.
\end{abstract}

\section{Introduction}

The purpose of this study was to develop hybrid materials that combine the properties of polymeric and inorganic substances which may serve as materials for high-rise constructions. These materials must be produced in one stage, have good mechanical properties, easy to be painted and connect with an inorganic base (concrete etc.). Because polymeric materials are important relaxation properties, in this work, we conducted experiments on the stress relaxation in the temperature range from 20 to $100^{\circ} \mathrm{C}$ at the constant deformation equal to $3 \%$.

\footnotetext{
* Corresponding author: MatseevichTA@mgsu.ru
} 


\section{The review of the literature}

A promising direction of improvement of technological, physical-mechanical, thermophysical and other properties of composite materials is the development and use of complex binders, among which of particular interest are hybrid organic-mineral composition [1-3]. One of the ways of producing of hybrid composites is the introduction into a polymer matrix of inorganic particles with the surface modified by the grafted organic molecules [45]. This allows obtain nanocomposites possessing unusual combination of properties.

Structure and properties of metal-polymer composites are described in [6]. In a review article [7] analyzed the structure and properties of polymer nanocomposites, in which matrix polymers have different chemical structure. Among them polymer-layered silicates, as well as composites in which the dispersed phase is nano-diamonds. Considered hybrid materials based on liquid crystal polymers. Significant attention is paid to chemical modification of nanoparticles and intermolecular interactions between the nanoparticles and the matrix polymer. In the other review article [8] presents the results of a structural study of hybrid nanomaterials. Among them the polymer-layered silicates, for example, nanodiamonds are described. The methods of modification of nanoparticles and their dispersion in the polymer matrix are discussed. The role of interactions between polymer matrix and fillers and the morphology of the nanoparticles occurring during processing, has also received considerable attention.

The series of works [9-12] on preparing and research of properties of hybrid materials, the modification of organic silicon compounds polyurethanes [9-10] and polyetherurethanes [11-12] have been published.

In our work, was used as inorganic component, an aqueous solution of silicates of alkali metals containing significant amounts of water. In this regard, as modifiers to the silicate compositions used isocyanat-containing chemical compounds (ICC), which have a high reactivity towards water. In the case of using aqueous solutions of silicates of alkali metals in combination with ICC manifests a chemical interaction between the components with the formation of covalent bonds.

\section{Materials and methods}

As objects of research we used the PIC (brand MELLIONATE MR-200), 2.4-TDI, epoxy oligomer (technical brand ED-20), LG.

To evaluate the heat resistance of the prepared compositions was determined by thermomechanical curves on the instrument TMA Q400 (TA Instruments).

To conduct micro-photographing used polarizing microscope POLAM-312P.

To evaluate the heat resistance of the obtained compositions was determined by thermomechanical curves (dependence of deformation on temperature) on the instrument TMA Q400 (TA Instruments).

The compression curves were measured on samples of size $4 \times 4 \times 6 \mathrm{~mm}$ at a deformation rate $4.68 \mathrm{~mm} / \mathrm{min}$.

IR spectra were measured on a Fourier transform infrared spectrometer Tensor 37 (Bruker) with a resolution of $2 \mathrm{~cm}^{-1}$. The investigated composition was placed between the windows of KBr. FTIR spectra with a resolution of $4 \mathrm{~cm}^{-1}$ were measured on Fourier spectrometer Vertex 70v with an attachment for FTIR GladiATR with diamond work item. Correction of FTIR spectra was performed using OMNIC programs.

As a research objects were used aqueous solution of sodium silicate (liquid glass LG), polyisocyanate (PIC), epoxy resin technical brand ED-20 and 2.4-toluenediisocyanate $(2,4-$ TDI). In the process of producing samples of polymer materials were also used fat-soluble 
dye (Sudan blue G). This dye is a derivative of aminoanthraquinone. In synthesized systems are used as a catalyst. Also the dye of the phthalocyanine green was used.

The samples of polymer materials were produced by fractional sequential addition of the original components. Mechanical mixing was carried out using a laboratory stirrer vane type. Initially the mixture of LG and PIC in the ratio of $32.9 \div 26.3 \mathrm{wt}$. \% was prepared. Under mechanical stirring for 3-4 min observed segregation of the mixture. Total processing time was 5-6 min to achieve homogeneity of the system. In order to remove the gaseous products of the resulting mixture was vacuumed at $40^{\circ} \mathrm{C}$ and $2 \mathrm{~mm} \mathrm{Hg}$. art. for 30 $40 \mathrm{~min}$. Then to reaction mixture were injected ED-20 in the amount of $34.2 \mathrm{wt}$ \%. In this case, the process of mixing in the reaction mixture of segregation has not been observed and the process time was about 3-4 minutes. Then, just as in the previous case, the resulting mixture was vacuumed under the same conditions.

The final stage consisted in the addition into the reaction mixture of an excess of 2.4TDI in the ratio of 4.7 wt. \%. Here the mixing process was accompanied by intensive increase of the viscosity of the mixture, and the duration of the process was 2-3 min; the reaction mixture was vacuumed for 20 to 25 minutes at a temperature of $40^{\circ} \mathrm{C}$. The amount of dye in the polymer mixtures was 1.9 wt. \%.

The prepared polymer mass was a homogeneous viscous liquid. The curing process of the mixture (precursor) was carried out by stepwise heating from 40 to $70^{\circ} \mathrm{C}$; the total curing time was 5-6 hours.

\section{The measurements conducting and the approximation of stress relaxation}

To conduct the stress relaxation in the uni-axial compression at the device for micromechanical test structures Dubov-Regel were prepared samples with a size of $4.0 \times 4.0 \times 6.0 \mathrm{~mm}$. The measurements were performed at deformation of $3 \%$ at different temperatures $\left(20-100^{\circ} \mathrm{C}\right)$. The rate of deformation was $1.87 \cdot 10^{-1} \mathrm{~mm} / \mathrm{min}$.

The stress relaxation curves were approximated in the linear region of mechanical behavior using the Boltzmann equation:

$$
\sigma=\sigma_{0}\left[1-\int_{0}^{t} T(\tau) d \tau\right],
$$

where $\sigma_{0}$ is the initial stress appearing in the output of the job "instantaneous" deformation; $T(\tau)$ is the memory function; $\tau$ is the current time, which runs through values from 0 to $t ; t$ is the end time.

For describing experimental data on stress relaxation used the memory function based on consideration of thermodynamic functions and their changes during the process [13-15]. The main assumption made in [13-15], is that the process of stress relaxation occurs as a result of interaction and diffusion of kinetic units (called often relaxers). The relaxers can be the groups of atoms arranged in repeating units, large fragments of macromolecules and their segments. The individual elements of the free volume (in this case, the "empty volume"), i.e., microcavity, stress raisers, etc. are also often. Together, these microcavities can merge, restructure and diffuse into the polymeric material during the stress relaxation, forming a structure that provides reduced stress relaxing. The process of restructuring has been proven by direct experiments for the study of the annihilation of positrons with the help of a special device that allows the relaxation process directly in the measuring chamber [16-17]. 
The emergence of two types of kinetic elements (relaxers and non-relaxers) and their diffusion in the material leads to the production of entropy of the system, which increases in the course of stress relaxation.

The entropy production (or the rate of change of entropy) is determined by the following relationship: $\frac{d S}{d t} \frac{1}{v}$ where $\mathrm{S}$ is the entropy; $t$ is the time; $v$ is the volume of the system. Considering the entropy of mixing of two types of kinetic units (relaxers and nonrelaxers), in the works [13-15] obtained the General form of the memory function:

$$
T(\tau)=-\frac{S_{0}}{k_{B} m}\left[\frac{1}{\alpha \ln \alpha+(1-\alpha) \ln (1-\alpha)}-\frac{1}{\ln 0.5}\right],
$$

where $m=m^{*} \int_{0}^{\infty} T^{*}(\tau) d \tau ; k_{B}$ is the Boltzmann constant; $m^{*}$ is the total number of kinetic units (in this case relaxers and non-relaxers per unit volume); $\alpha$ is the share relaxers of the total kinetic units, $T^{*}(\tau)$ is the variable part of the memory function; $S_{0}$ is the initial entropy of the system (specimen).

If the change in $\alpha$ over time $\tau$ due to the interaction between relaxers and their transition to non-relaxers material, the following kinetic equation takes place:

$$
\frac{d c}{d \tau}=k C^{n}
$$

where $k$ is the constant of reaction rate; $C$ is the concentration.

The result:

$$
C=\frac{C_{0}}{\left.\left[1+C_{0}^{n-1}(n-1) k \tau\right]\right]^{\frac{1}{n-1}}}
$$

where $C_{0}$ is the initial concentration of any type of relaxers (for simplicity assumed that these concentrations are equal for different types of relaxers). Then:

$$
\alpha=\frac{C}{C_{0}}=\frac{1}{\left(1+k^{*} \tau / \beta\right)^{\beta}},
$$

where $k^{*}=k C_{0}^{n-1} ; \beta=\frac{1}{n-1} ; n$ is the reaction order.

If the relaxation process is limited by the rate of interaction of relaxers, there is the memory function of $T_{1}(\tau)$, which is obtained by substituting (5) into (2).

If the relaxation process is limited by the diffusion rate of non-relaxers, the value $\alpha$ is determined from the relation [18]:

where $0<b<1$ and $a$ is a constant.

$$
(1-\alpha)=a \tau^{b / 2}
$$

It is the memory function of $T_{2}(\tau)$, which is obtained by substitution of (6) into equation (2):

$$
T_{2}(\tau)=-\frac{S_{0}}{k_{B} m_{2}}\left[\frac{1}{a \tau^{\gamma} \ln a \tau^{\gamma}+\left(1-a \tau^{\gamma}\right) \ln \left(1-a \tau^{\gamma}\right)}-\frac{1}{\ln 0.5}\right]
$$

where $\gamma=b / 2$.

Approximation curves of the stress-relaxation was performed using a personal computer, into the software which was pre-recorded tabulated values of the variable parts of the memory functions which are given in [13-15] were incorporated. Automatically the selection of those parameter values for which the sum of squares of deviations of 
experimental values of the stress relaxing from the settlement was minimal and the correlation coefficient is maximum.

\section{The results of the study}

The study by the method of IR spectroscopy shows that the obtained polymer has a complex structure. Isocyanate groups remain in the final product in very small quantities, turning into NH-groups of the polyurethane. The formation of isocyanurate cycles in significant quantities is not observed.

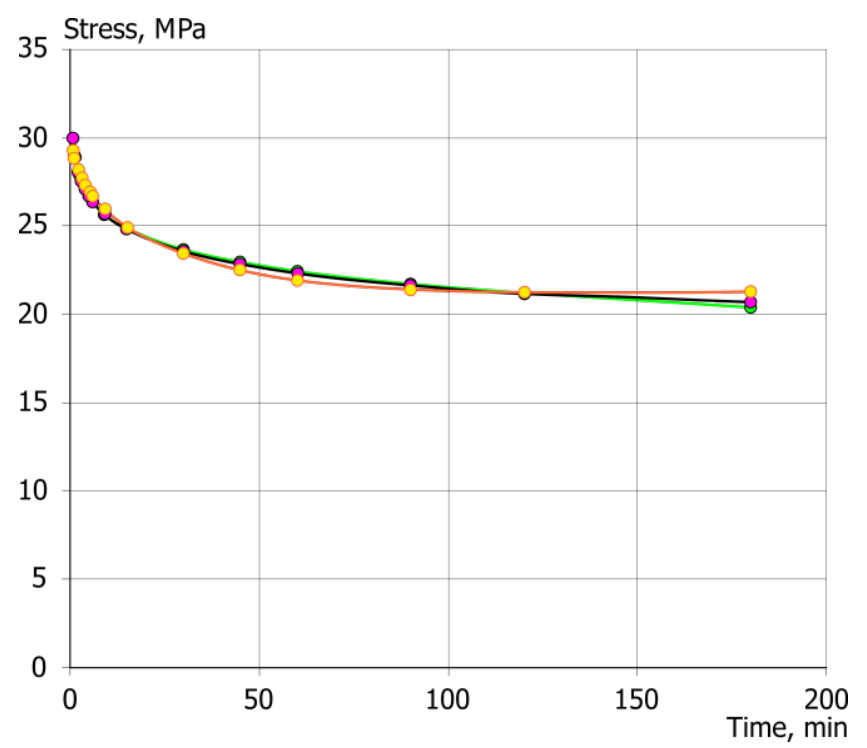

Fig. 1. The approximation the stress relaxation curve. Temperature is $20^{\circ} \mathrm{C}$.

Figure 1 shows an example of experimental curve of stress relaxation for painted sample and the calculated curves obtained using the memory functions $T_{1}(\tau)$ and $T_{2}(\tau)$. Figure 1 is taken from the monitor of the computer program "Cascade" (INEOS RAS). It is seen that the approximation provides a good convergence of calculated and experimental data. In all cases the coefficients of correlation $r$ close to 1 .

Values of $r$ for most samples slightly higher when using the memory function $T_{1}(\tau)$ than when using the memory function $T_{2}(\tau)$. In the first case, this means that the limiting stage of the process is the rate of interaction of relaxers and, and in the second case, the rate of diffusion of the non-relaxers. The rate constant of the interaction of relaxers for almost all samples is equal to $0.001 \mathrm{~min}^{-1}$.

The values of initial and final stresses and the compressive strength are shown in Table 1. It is clear that our materials have high strength at different temperatures and relatively little stress relaxation.

Table 1. The properties of the painted samples.

\begin{tabular}{|c|c|c|c|}
\hline Temperature, ${ }^{\circ} \mathrm{C}$ & $\begin{array}{c}\text { Tensile strength at } \\
\text { compression, } \mathrm{MPa}\end{array}$ & $\begin{array}{c}\text { The initial stress, } \\
\sigma_{0}, \mathrm{MPa}\end{array}$ & $\begin{array}{c}\text { The equilibrium (final) } \\
\text { tension, } \sigma_{\infty}, \mathrm{MPa}\end{array}$ \\
\hline 18 & 32.0 & 30.0 & 20.4 \\
\hline 50 & 24.0 & 26.0 & 16.2 \\
\hline 85 & 18.0 & 16.7 & 8.8 \\
\hline 100 & 17.5 & 16.1 & 7.7 \\
\hline
\end{tabular}




\section{Conclusion}

The painted materials based on sodium LG, 2,4-TDI and PIC, modified ED-20, have been prepared and investigated. Curing in the mild conditions at temperatures of $60-70^{\circ} \mathrm{C}$ leads to the formation of network structures. Monitoring method IR spectroscopy showed that the final product remains the only band of stretching vibrations of NH-groups. The IR spectrum corresponds to mainly the spectrum of the epoxide, and the difference spectrum matches the spectrum of the polyurethane. Chemical interaction is via the terminal groups of epoxy oligomer, i.e. for oxiranyl cycles.

Found that the modification of the initial mixtures of ED-20 results in more uniform grain structure of the composites and improving their mechanical properties. The detailed study of the process of stress relaxation at different temperatures in the range $20-100^{\circ} \mathrm{C}$ is provided. The physical parameters of the memory functions are evaluated. The initial relaxation modulus reached values of $1000 \mathrm{MPa}$ at $20^{\circ} \mathrm{C}$, and $540 \mathrm{MPa}$ at $100^{\circ} \mathrm{C}$. For nonmodified epoxide starting materials of the relaxation module was $730 \mathrm{MPa}$ at $20^{\circ} \mathrm{C}$ and at $100^{\circ} \mathrm{C}$ to 520 . Obtained master curves provide prediction relaxation behavior for large durations of relaxation. The greatest relaxation module has material containing an increased amount of PIC.

Availability of simple technology for producing hybrid materials based on LG, their excellent mechanical properties and the ability to be painted to turn enables their use as decoration materials for the high-rise constructions.

\section{References}

1. M.A. Meador, E.F. Fabrizio, F. Ilhan, A. Dass, G. Zhang, P. Vassilarias, J.C. Johnston, N. Leventis, J.Chem. Mater., 17, 1085 (2005).

2. D.J. Boday, D.A. Loy, Polymer Preprints, 50, 282 (2009).

3. D.M. Delozier, R.A. Orwoll, J.F. Cahoon, J.S. Ladislaw, J.G. Smith, J.W. Connell, Polymer, 44, 8, 2231 (2003).

4. V.I. Roldugin, O.A. Serenko, E.V. Getmanova, N.A. Karmishina, S.N. Chvalun, A.M. Muzafarov, Dokl. Akad. N., 449, 5, 552 (2013).

5. A.S. Zhil'tsov, I.B. Meshkov, T.S. Kurkin, O.B. Gorbatsevich, V.V. Kazakova, A.A. Askadskii, O.A. Serenko, A.N. Ozerin, A.M. Muzafarov, Ros. Nanotekhn., 8, 9-10, 46 (2015).

6. A.D. Pomogaylo, Ros. Khim. Zh., XLVI, 5, 64 (2002).

7. V.A. Gerasin, E.M. Antipov, V.V. Karbushev, V.G. Kulichikhin, G.P. Karpacheva, R.V. Tal'roze, Ya.V. Kudryavtsev, Usp. Khim., 82, 4, 303 (2013).

8. A.V. Povolotskaya, A.V. Povolotskiy, A.A. Man'shina, Usp. Khim., 84, 6, 579 (2015).

9. H. Sardon, L. Irusta, M.J. Fernandez-Berridi, M. Lansalot, E. Bourgeat-Lami, Polymer, 51, 5051 (2010).

10. K. Szwarc-Rzepka, T. Szatkowski, F. Ciesielczyk, T. Jesionowski, Physicochem. Probl. of Mineral Proc., 49, 2, 673 (2013).

11. A. Rekondo, M.J. Fernarndez-Berridi, L. Irusta, Europ. Polymer J., 42, 2069 (2006).

12. M.S. Shabalina, E.A. Antipova, G.A. Khlebov, Kauchuk i rezina, 5, 26 (2014).

13. 13 A.A. Askadskii, Computational Materials Science of Polymers (CISP, 2003)

14. A.A. Askadskii, V.I. Kondrashchenko, Komp'yuternoe materialovedenie polimerov. (Nauch. Mir, 1999). 
15. A.A. Askadskii, A.R. Khokhlov, Vvedenie v fiziko-khimiyu polimerov (Nauch. Mir. 2009).

16. A.A. Askadskii, S.A. Tishin, V.V. Kazantseva, O.V. Kovriga, Vysokomolek. Soed., A32, 12, 2437 (1990).

17. A.A. Askadskii, S.A. Tishin, M.I. Tsapovetskiy, V.V. Kazantseva, O.V. Kovriga, V.A. Tishin, Vysokomolek. Soed., A34, 1, 62 (1992).

18. R.J. Gaylord, B. Joss, J.T. Bendler, E.A. Di Marzio, Brit. Polymer J., 17, 2, 126 (1985). 